\title{
Delayed Diagnosis of Complete Tracheal Transection
}

\author{
Reza Ershadi* \\ Department of thoracic surgery, Valiasr Hospital, Tehran university of medical science, Iran
}

Received: September 24, 2020; Published: October 14, 2020

*Corresponding author: Reza Ershadi, Department of Thoracic surgery, Valiasr Hospital, Tehran university of medical science, Bagherkhan street, Tehran Iran

\begin{abstract}
Tracheal injuries are relatively rare, but their mortality rate is fairly high. Complete disruption of trachea is extremely rare, and a systematic approach is needed for early diagnosis and favourable outcome. This is a case report of 17 -year-old man who arrived in the emergency room after a motor vehicle accident .He was agitated and in respiratory distress with labored breathing and urgently intubated orotracheally. In the first flexible bronchoscopy ,diagnosis of tracheal transection was missed. On the seventh day due to saturation drop and high peak ventilator pressures ,the flexible bronchoscopy examination was carried out in the operating room. This showed complete tracheal transection in midportion. Neck exploration demonstrated complete tracheal transection. The area was debrided , and primary end-to-end anastomosis was performed. . The patient was extubated at the end of surgery.
\end{abstract}

Keywords: Delayed diagnosis; Trachea; Transection

\section{Introduction}

Traumatic tracheal injury after blunt neck trauma is rare; however, most patients with complete tracheal transection usually die at the scene due to loss of airway [1]. The few, who survive and arrive at a hospital, pose a diagnostic and therapeutic challenge to the trauma team. These patients may suffer fatal outcomes when misdiagnosed or long-term complications, if treated improperly.
Diagnosis is usually obscure as the symptoms may not be directed towards the disease. Early diagnosis and treatment of tracheal injuries lead to the best outcome [2]. In this paper, our experience with one survivor of complete tracheal transection caused by blunt trauma that diagnosed after one week, was reported.

\section{Case Report}

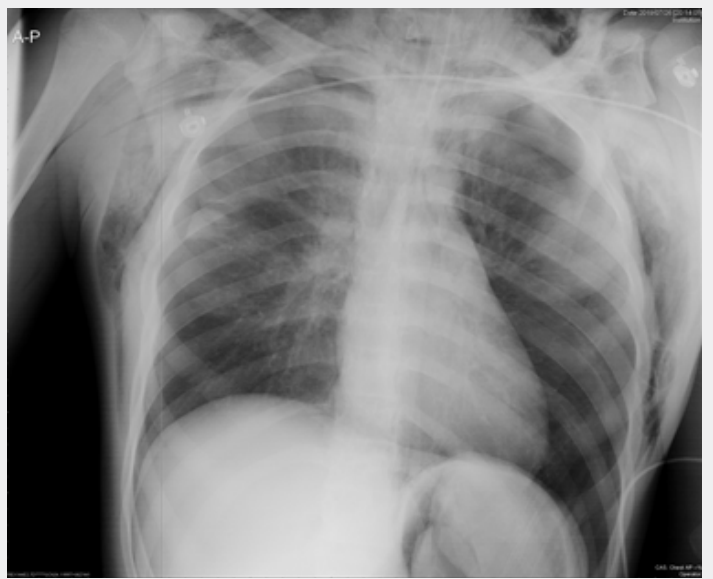

Figure 1: Supine chest radiograph showing pneumomediastinum and neck and chest subcutaneous emphysema. 


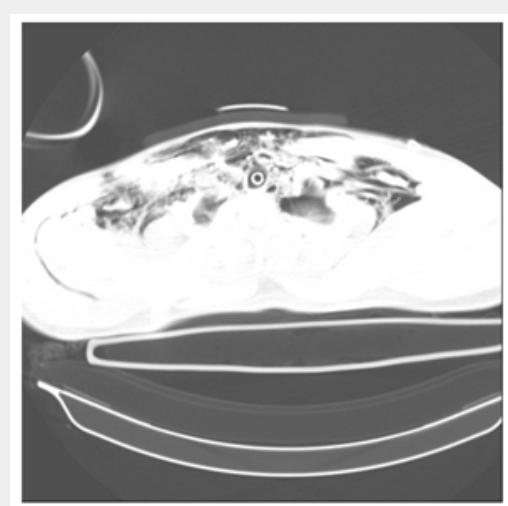

A

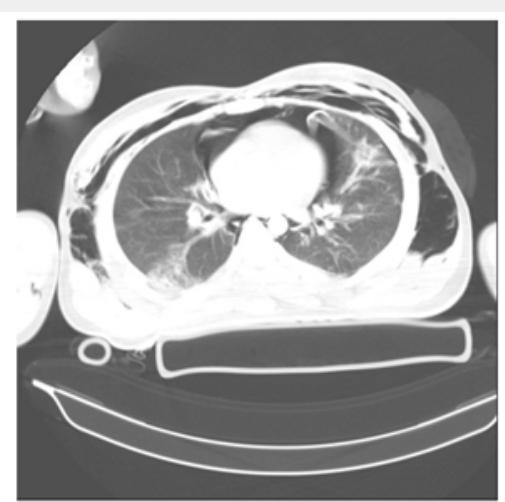

B

Figure 2: (A) CT image of the neck showing subcutaneous emphysema.

(B) CT image of chest showing pneumomediastinum , pulmonary contusion and subcutaneous emphysema.

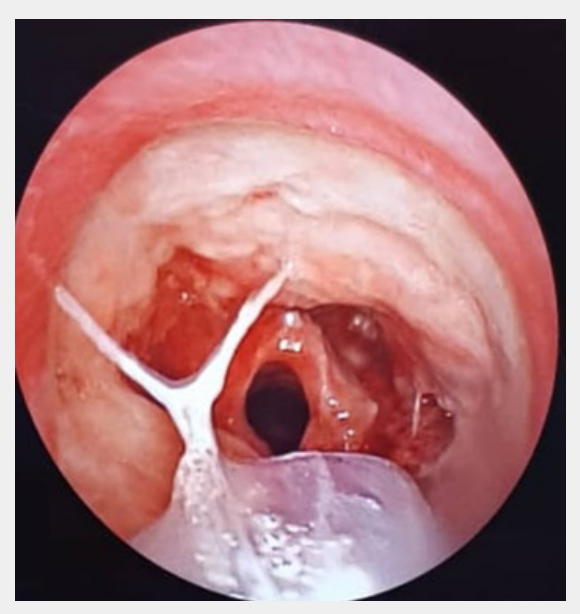

Figure 3: Fiberoptic bronchoscopy demonstrated complete tracheal separation.

A 17-year-old man arrived in the emergency room after a motor vehicle accident. He was agitated and in respiratory distress with labored breathing and urgently intubated orotracheally. The vital signs included a blood pressure of $110 / 80 \mathrm{mmHg}$, a heart rate of 115 beats/ min, and an axillary temperature of $36.4^{\circ} \mathrm{C}$. Patient had crepitus on his neck and chest area. . Pneumomediastinum and subcutaneous emphysema were seen on a supine chest radiograph (Figure1). Computed tomographic scan (CT) of the neck and chest revealed pneumomediastinum, pulmonary contusion and subcutaneous emphysema in the neck and chest (Figure2). Because of concern for suspected tracheobronchial

injury ,flexible fiberoptic bronchoscopy in the emergency room was performed but no finding in favor of tracheal injury was reported and tracheal transection was miss. During one-week admission of the patient in the ICU ,he had occasionally high peak ventilator pressures but saturated well. On the seventh day due to saturation drop and high peak ventilator pressures ,the flexible bronchoscopy examination was carried out in the operating room. This showed complete tracheal transection in midportion (Figure 3). Neck exploration demonstrated complete tracheal transection. The area was debrided, and primary end-to-end anastomosis was performed. . The patient was extubated at the end of surgery . After one week the patient was discharged.

\section{Discussion}

Complete tracheal transection in blunt cervical trauma is uncommon occurrence. Tracheal injuries are life threatening with mortality rate of $40 \%$. Timely and proper airway management is life-saving [3]. Signs and symptoms may be subtle in tracheal injuries and also relatively non-specific correlating poorly with the severity of the underlying injuries. Intact peritracheal tissue may provide a life-saving conduit for gas exchange through the disruption [4]. Most common presentations are respiratory distress, dyspnea, poor gas exchange and hemoptysis [5]. Cyanosis and serious respiratory embarrassment is present 
in $30 \%$ of the cases. Another common symptom is hoarseness or dysphonia, occurring in $46 \%$ of the patients [6]. The most common signs of airway injury reported in most series are subcutaneous emphysema (35-85\%), pneumothorax (20-50\%) and hemoptysis (14-25\%); however, the lack of specificity and the occult nature of the injury frequently result in a delayed diagnosis [7]. Deep cervical emphysema and pneumomediastinum are seen in $60 \%$ of the patients with tracheobronchial injuries [6]. Many tracheobronchial injuries are not diagnosed immediately (25$68 \%$ ) [5]. Physicians need to maintain a high index of suspicion related to non-specific signs such as dyspnea, cough, subcutaneous emphysema and hemoptysis. The mechanism of injury, vocal changes and rapidly expanding subcutaneous emphysema in the neck are important clues [8]. Clinical examination is followed by radiologic imaging, angiography, CT and tracheo-bronchioesophagoscopy [9].

Accurate interpretation of the chest radiograph is essential in the early diagnosis of occult upper-airway injury. A CT scan can be performed if diagnosis is uncertain on plain films [8]. Preoperative CT can be useful in assessing associated laryngeal injuries or other unsuspected chest injuries that should be dealt with at the time of surgical exploration. CT is contraindicated in hemodynamically unstable trauma patients or patients with unstable airways [6]. Helical CT with 3D reconstruction should be considered a suitable 'screening' test in a trauma patient suspected of tracheal rupture and may help the clinician in the decision to perform a bronchoscopy on the patient [7]. The best diagnostic investigation is bronchoscopy. Flexible bronchoscopy should be carried out first to determine the location and extent of the injury [5]. Some reports agreed that there is a slight possibility that airway problems could be missed and therefore repeat fiberoptic bronchoscopy follow-up should be performed if the clinical situation suggests an abnormality $[10,11]$. Principles of management includes prompt airway establishment, immediate exploration of the wound with appropriate investigation. Surgical repair is the treatment of choice for tracheal transection that includes complete repair of trachea with end-to-end anastomosis. Complete transection of the trachea should be managed by careful suturing and being cautious to avoid damage to the recurrent laryngeal nerves [12].

\section{Conclusion}

Complete tracheal transection in blunt trauma is uncommon occurrence and is life threatening. Signs and symptoms may be subtle in tracheal injuries. This report agreed that there is a slight possibility that airway problems could be missed and therefore repeat fiberoptic bronchoscopy follow-up should be performed if the clinical situation suggests an abnormality .Timely diagnosis, skillful airway management and prompt surgical repair are important for positive outcomes.

\section{Acknowledgement}

Thanks to anesthesiologist and fellowship of thoracic surgery.

Conflict of interest statement: The author has not conflict of interest.

\section{References}

1. Dertsiz L, Arici G, Arslan G, Demircan A (2007) Acute tracheobronchial injuries: early and late term outcomes. Ulus Travma Acil Cerrahi Derg 13: $128-134$.

2. Hamid UI, Jones JM (2013) Combined tracheoesophageal transection after blunt neck trauma. J Emerg Trauma Shock 6: 117-122.

3. Minard G, Kudsk KA, Croce MA, Cicala RS, Fabian TC ( 1992) Laryngotracheal trauma. Am Surg 58: 181-187.

4. Reza Ershadi, Asghar Hajipour, Mohamadrahim Vakili (2017) Complete cricotracheal transection due to blunt neck trauma without significant symptoms. Journal of Surgical Case Reports 2017(6).

5. Wong EH, Knight S (2006) Tracheobronchial injuries from blunt trauma. ANZ J Surg 76: 414-415.

6. Karmy-Jones R, Wood DE (2007) Traumatic injury to the trachea and bronchus. Thorac Surg Clin 17: 35-46.

7. Le Guen M, Beigelman C, Bouhemad B, Wenjïe Y, Marmion F, Rouby JJ (2007) Chest computed tomography with multiplanar reformatted images for diagnosing traumatic bronchial rupture: a case report. Crit Care 11: R94.

8. Hsiao SH, Chen BS, Lee TM, Hsu SY, Lai YY (2009) Delayed diagnosis of complete tracheal transection after blunt neck trauma. Tzu Chi Med J 21: 77-80.

9. Veit JA, Metternich F (2008) Management of traumatic tracheal injuries: presentation of a rare case and review of the literature. [Article in German] Laryngorhinootologie 87: 270-273. [Abstract]

10. FJ Baumgartner, B Ayres, C Theuer (1997) Danger of false intubation after traumatic tracheal transection. Ann Thorac Surg 63: 227-228.

11. KS Hara, UB Prakash (1989) Fiberoptic bronchoscopy in the evaluation of acute chest and upper airway. Trauma Chest 96: 627-630.

12. Roxburgh JC (1987) Rupture of the tracheobronchial tree. Thorax 42 : 681-688. 
(CC) (i) This work is licensed under Creative Commons Attribution 4.0 Licens DOI:10.19080/OAJS.2020.12.555838

\section{Your next submission with Juniper Publishers will reach you the below assets}

- Quality Editorial service

- Swift Peer Review

- Reprints availability

- E-prints Service

- Manuscript Podcast for convenient understanding

- Global attainment $\mathrm{f}$ or your research

- Manuscript accessibility in different formats (Pdf, E-pub, Full Text, Audio)

- Unceasing customer service

Track the below URL for one-step submission https://juniperpublishers.com/online-submission.php 